\title{
Evaluation of four different coagulants used for chemical dephosphorization of membrane bioreactor effluent
}

\author{
Qin Cai, Hui-qiang Li, and Ping Yang* \\ College of Architecture and Environment, Sichuan University, Chengdu 610065, China.
}

\begin{abstract}
A continuous flow chemical reactor was constructed to study the dephosphorization effect on the effluent of the oxygen-limited internal-loop fluidized membrane bioreactor (IF-MBR) for domestic sewage treatment. Removal effect of total phosphorus (TP) by four coagulants of $\mathrm{AlCl} 3, \mathrm{FeCl} 3$, polyaluminum ferric chloride (PAFC) and polyaluminium chloride (PAC) was evaluated. Results showed that when the ratio of coagulants to TP was 5 (coagulants in terms of $\mathrm{Fe}$ and $\mathrm{Al}$ ), the removal efficiency of $\mathrm{TP}$ by $\mathrm{FeCl} 3$ was $92.5 \%$ and the addition of $\mathrm{FeCl} 3$ resulted in an increase in the chromaticity of the effluent. PAC and PAFC had good removal of TP, and the removal percentage achieved 96.2 and 97.4, respectively. However, the flocs they produced were small and light, and the performance in settlement was poor. $\mathrm{AlCl} 3$ performed well as a phosphorus removal agent, the removal rate of TP reached 97.4\%, and the flocs were large and dense. Based on this, $\mathrm{AlCl} 3$ was the best choice for IF-MBR and then the experiment further optimized the Al/P ratio. Results showed that when the Al/P ratio was above 1:1, the effluent TP concentration was lower than $1 \mathrm{mg} / \mathrm{L}$; when the ratio was higher than $2.5: 1$, the effluent TP was lower than $0.5 \mathrm{mg} / \mathrm{L}$.
\end{abstract}

\section{Introduction}

Excessive phosphorus (P) would lead to excessive growth of aquatic plants and algae, and even severe eutrophication. Once the eutrophication of water bodies was formed, it would lead to severe eutrophication. Specifically, aquatic organisms absorb nitrogen $(\mathrm{N})$ and $\mathrm{P}$, and $\mathrm{N}$ and $\mathrm{P}$ would be released again after they died, which would increase eutrophication [1]. Typical biotechnological techniques such as oxidation ditch (OD), sequencing batch reactors (SBR) and membrane bioreactor (MBR) have been widely used in domestic wastewater treatment for removal of phosphorus. However, the biological dephosphorization effect is bad, and it is difficult to meet the standard of effluent. Therefore, many sewage treatment plants use coagulation to enhance phosphorus removal.

Coagulation is a phosphorus removal method of high processing efficiency, fast processing speed and low-cost. Among them, metal salts are widely used in practice [2-3]. Conventional coagulants include aluminum and iron (III) salts. Compared with the inorganic salt, the inorganic polymer salt is characterized by a high flocculation rate, high density, fast sedimentation speed and strong adaptability to water quality. But it is necessary to determine the appropriate form and dosage of coagulant for each kind of wastewater by experiment, since the removal effect of phosphorus depends on the quality of the wastewater before treatment and the required water quality [4].

In China, the application of MBR in domestic water treatment began in 1995 [5]. There were few studies on chemical phosphorus removal in actual MBR projects, and they were mainly concentrated on pre-removal and simultaneous removal [5-6]. However, pre-removal and simultaneous chemical dephosphorization caused that the coagulants had not only bad effect on the microbial activity, but also required excessive addition of coagulants due to polymerization of other substances (such as colloidal particles, biodegradable organic compounds), which made the sludge increase [6-7]. Based on this, this study used post-phosphorus removal on the effluent of the IF-MBR. It enabled the phosphorus-containing sludge to be discharged separately and be reused [7]. Moreover, the amount of suspended solid (SS) and dissolved organic matter in the membrane effluent was small, and there were no waste of the coagulants.

\section{Material and methods}

\subsection{Experimental set-up and operating conditions}

The reactor was made of plexiglass and had an effective volume of $10 \mathrm{~L}$. It was divided into three zones: coagulation, sedimentation and filtration. The coagulation zone was $60 \times 60 \times 150 \mathrm{~mm}$ and the effective volume was $4.8 \mathrm{~L}$. A $30 \times 60 \mathrm{~mm}$ vertebral body was placed around the bottom of this zone to avoid a dead zone. The filtration was single-layer, the filtration zone was $60 \times 60 \times 100 \mathrm{~mm}$, the filter material was mainly quartz sands, and the particle size was 1-2 mm. The physical parameters of quartz sands are: specific gravity, $2.66 \mathrm{~g} / \mathrm{cm}^{3}$; bulk density, $1.76 \mathrm{~g} / \mathrm{cm}^{3}$; porosity, 43-47\%; Mohs hardness, 7.5 .

\footnotetext{
*Corresponding author: yangpinga301@163.com
} 
The water continuously entered in and discharged from the reactor at a speed of $2.4 \mathrm{~L} / \mathrm{h}$. The influent flowed into the coagulation zone from the bottom through a peristaltic pump (Langer, China), then into the sedimentation zone through the top, and finally out after the filtration. The coagulation zone was mechanically agitated at a speed of 400 rotations/min, which was beneficial to the rapid dispersion of coagulants. After the influent was in full contact with the coagulant, it flew through the sedimentation zone and the filtration zone, and the effluent was directly measured without passing through the filter paper. . The overall hydraulic retention time (HRT) of the reactor was $4 \mathrm{~h}$ with half of the coagulation zone. The discharged and backwashed cycle of the sludge was $12 \mathrm{~h}$. The reaction temperature was not controlled throughout the chemical dephosphorization, and the influent temperature was $26{ }^{\circ} \mathrm{C}$. TP was measured by the ammonium molybdate spectrophotometric method [8].

\subsection{Schematic diagram and operating conditions of the IF-MBR}

The experimental influent was the effluent of the IF-MBR, and the schematic diagram of the IF-MBR was shown in Figure 1. It was made of Plexiglas, with an effective volume of $19 \mathrm{~L}$, had an attached settling chambers at the top for gas disengaged The exterior of the IF-MBR was wrapped up by black paper to avoid light. A submerged hollow-fiber polyvinylidenfluoride (PVDF) membrane module (motian, tianjing, China) with nominal pore size of $0.1 \mu \mathrm{m}$ and an effective total membrane surface area of 0.3 $\mathrm{m}^{2}$ was installed above aeration ports in the top of the draft tube. 30-40 mesh porous polymer carriers were added into the reactor with a packing ratio of about $5 \%$.

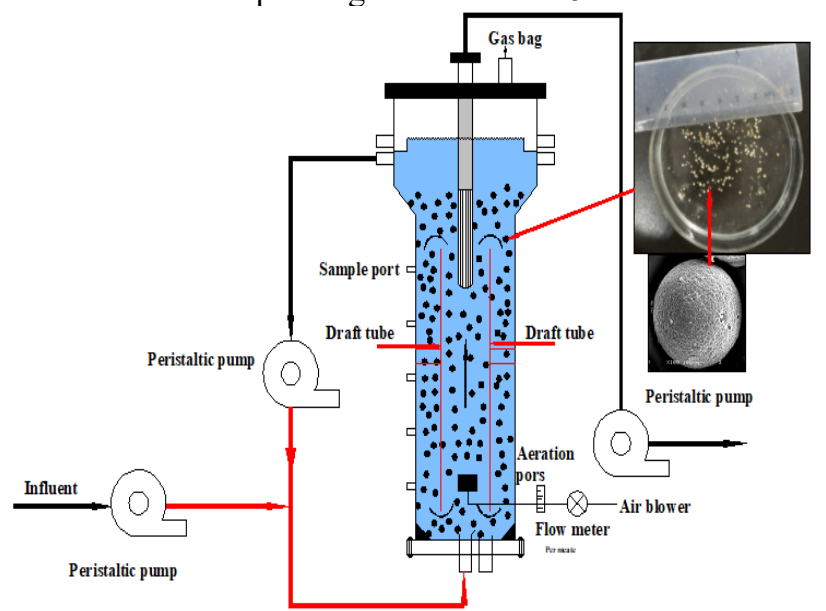

Fig. 1. Schematic diagram of the IF-MBR [9].

Physical parameters of the polymer porous carrier were summarized as follows: wet packing density of 1010.00 $\mathrm{kg} / \mathrm{m}^{3}$, skeletal density of $1320.00 \mathrm{~kg} / \mathrm{m}^{3}$, pore volume of $0.301 \mathrm{ml} / \mathrm{g}$ and wet surface area of $5357.00\left(\mathrm{~m}^{2} / \mathrm{m}^{3}\right)$.

HRT of the IF-MBR was $8 \mathrm{~h}$, DO was kept at $0.5 \mathrm{mg} / \mathrm{L}$. The temperature was thermostatically controlled at $26^{\circ} \mathrm{C}$ by means of a resistance wire heating.

The IF-MBR was conducted using a synthetic wastewater to avoid any fluctuation in the feed concentration and provide a continuous source of biodegradable organic pollutants. The composition of the synthetic wastewater was as follows: glucose, $300 \mathrm{mg} / \mathrm{L}$; $\left(\mathrm{NH}_{4}\right)_{2} \mathrm{SO}_{4}, 188.6-242.9 \mathrm{mg} / \mathrm{L} ; \mathrm{KH}_{2} \mathrm{PO}_{4}, 43.9 \mathrm{mg} / \mathrm{L}$; and 1 $\mathrm{mL} / \mathrm{L}$ of a trace element solution.

One liter of trace element solution contained $15.0 \mathrm{~g} / \mathrm{L}$, EDTA; $1.1 \mathrm{~g} / \mathrm{L}, \quad\left(\mathrm{NH}_{4}\right)_{6} \mathrm{Mo}_{7} \mathrm{O}_{2} \cdot \quad 4 \mathrm{H}_{2} \mathrm{O} ; 0.99 \mathrm{~g} / \mathrm{L}$, $\mathrm{MnCl}_{2} \cdot 4 \mathrm{H}_{2} \mathrm{O} ; 4.2 \mathrm{~g} / \mathrm{L}, \mathrm{CaCl}_{2} \cdot \mathrm{H}_{2} \mathrm{O} ; 0.24 \mathrm{~g} / \mathrm{L}, \mathrm{CoCl}_{2} \cdot 6 \mathrm{H}_{2} \mathrm{O}$; $0.014 \mathrm{~g} / \mathrm{L}, \mathrm{H}_{3} \mathrm{BO}_{4} ; 5.0 \mathrm{~g} / \mathrm{L}, \mathrm{MgSO}_{4} \cdot 7 \mathrm{H}_{2} \mathrm{O} ; 5.0 \mathrm{~g} / \mathrm{L}$, $\mathrm{FeSO}_{4} \cdot 7 \mathrm{H}_{2} \mathrm{O} ; \quad 0.25 \mathrm{~g} / \mathrm{L}, \quad \mathrm{CuSO}_{4} \cdot 5 \mathrm{H}_{2} \mathrm{O} ; 0.21 \mathrm{~g} / \mathrm{L}$, $\mathrm{NiSO}_{4} \cdot 6 \mathrm{H}_{2} \mathrm{O}$. $\mathrm{NaHCO}_{3}$ with $1 \mathrm{~g} / \mathrm{L}$ was added to the influent to maintain the $\mathrm{pH}$ of the ITFB-MBR suspension between 7.8 and 8.4 .

The IF-MBR experiment results showed that the biological dephosphorization was mainly based on denitrification dephosphorization and inorganic precipitation under the oxygen-limited state. In the IFMBR, when TP concentration in influent was $10 \mathrm{mg} / \mathrm{L}$, the removal rate was $20-45 \%$; when TP concentration in influent was $5 \mathrm{mg} / \mathrm{L}$, the removal rate was $36-52 \%$.

During this chemical dephosphorization experiment, the TP in the IF-MBR was kept at $5 \mathrm{mg} / \mathrm{L}$, and the key characteristics of the effluent were shown in Table 1.

Table 1. Key characteristics of the IF-MBR effluent

\begin{tabular}{|c|c|c|c|c|c|}
\hline Parameter & \multirow{2}{*}{$\mathrm{pH}$} & \multicolumn{4}{|c|}{$\mathrm{mg} / \mathrm{L}$} \\
\cline { 3 - 6 } & & $\mathrm{COD}$ & $\mathrm{NH}_{4}^{+}-\mathrm{N}$ & $\mathrm{TN}$ & $\mathrm{TP}$ \\
\hline Value & $7.6-7.8$ & $20-40$ & $0-4$ & $11-14$ & $2.3-3.6$ \\
\hline
\end{tabular}

\subsection{Selection of the type and dosage of the coagulants}

$\mathrm{FeCl}_{3}, \mathrm{AlCl}_{3}, \mathrm{PAFC}$ and PAC were chosen as typical coagulants. Four salts were in excess and at a ratio of $5: 1$ to TP $\left(\mathrm{FeCl}_{3}\right.$ and $\mathrm{AlCl}_{3}$ were in terms of $\mathrm{Fe}$ and $\mathrm{Al}$, respectively) to select the optimal coagulant. The $\mathrm{pH}$ was not adjusted prior to the addition of the coagulants. Then, a series of ratios of the optimal coagulant to TP were selected between the theoretical value of $1: 1$ and the excess of $5: 1,1: 1,2.5: 1,3.6: 1$ and $4.3: 1$, respectively. And the optimum volume was determined by the above experiment.

\section{Results}

The removal effect of four different excess coagulants on $\mathrm{TP}$ was shown in Figure 2. When the ratio of $\mathrm{AlCl}_{3}$ (in terms of $\mathrm{Al}$ ), $\mathrm{FeCl}_{3}$ (in terms of $\mathrm{Fe}$ ), $\mathrm{PAFC}$ and $\mathrm{PAC}$ to $\mathrm{P}$ was $5: 1$, the average effluent TP was $0.08 \mathrm{mg} / \mathrm{L}, 0.23 \mathrm{mg} / \mathrm{L}$, $0.10 \mathrm{mg} / \mathrm{L}, 0.08 \mathrm{mg} / \mathrm{L}$, and the corresponding removal rate was $97.4 \%, 91.4 \%, 96.2 \%, 97.4 \%$. This indicated that four coagulants had good performance on TP removal.

Specifically, the removal efficiency of TP using $\mathrm{FeCl}_{3}$ was lowest among the four coagulants, and the optimal efficiency was $92.5 \%$ when $\mathrm{FeCl}_{3}$ was at a ratio of 5:1 to TP. In addition, $\mathrm{Fe}^{3+}$ formed soluble contaminants with organic matter (such as humus), resulting in an increase in the chromaticity of the effluent [10]. Based on this, $\mathrm{FeCl}_{3}$ had the worst effect for this system. PAC and PAFC had good removal effect of TP, but the flocs they produced were small and light, which indicated they performed poorly in terms of settlement. The reason may be that the influent of the reactor was the effluent of IF-MBR, and the 
SS was almost 0 . According to the mechanism of polymer adsorption bridging, the polymer generally has a long chain structure with a linear or branched shape. They are dispersed in water, react with the functional groups of the colloidal substances and adsorb each other, so that the high molecular polymer could realize the bridging effect [11]. Less SS in water meant that the amount of colloidal particles was small, so the long chain structure adsorbed the original colloidal particles rather than new ones. As a result, the bridging effect cannot be exerted and the colloidal particles were in a stable state. Therefore, PAC and PAFC were not easy to form large and dense flocs, and were not precipitated quickly. Still a small amount of flocs flowed out with the effluent after filtration. Therefore, the best coagulant for this system was $\mathrm{AlCl}_{3}$.

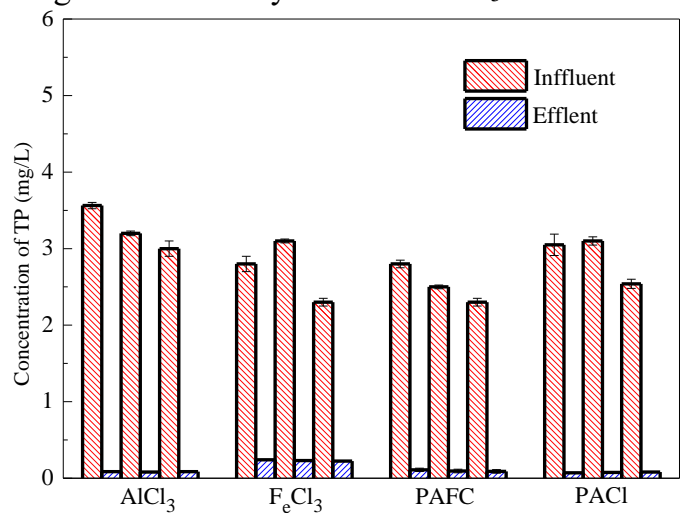

Fig. 2. The concentration of TP in the influent and effluent (the ratio of every coagulant to TP was 5:1).

On the basis of good TP removal efficiency, the amount of coagulant should be minimized to reduce costs. The relationship between the amount of coagulant and the removal rate was shown in Figure 3. The influent TP was $3.0 \mathrm{mg} / \mathrm{L}$, the experiment set four $\mathrm{Al} / \mathrm{P}$ ratios of $4.3: 1,3.6: 1$, $1: 1$ and $2.5: 1$, and the TP removal rate was all above $50 \%$. When $\mathrm{Al} / \mathrm{P}$ addition ratio was $4.3: 1$ and 3.6:1, the effluent TP was lower than $0.3 \mathrm{mg} / \mathrm{L}$, and the removal rate was above $94.3 \%$. To keep the effluent TP lower than $1.0 \mathrm{mg} / \mathrm{L}$, the $\mathrm{Al} / \mathrm{P}$ optimal ratio was $1: 1$. And the optimal ratio was 2.5:1 to keep the effluent TP lower than $0.5 \mathrm{mg} / \mathrm{L}$. According to the mechanism of phosphorus removal by aluminum salts, the main reaction was the precipitation of aluminum phosphate and the secondary reaction was hydrolysis of aluminum salts. Theoretically, the main reaction is the main removal way of dephosphorization, and the amount of aluminum salt can reach 1:1 with the removed phosphorus. But the influent $\mathrm{pH}$ in this experiment was 7.6-7.8, so there was the secondary reaction. Moreover, some studies had found that the adsorption of aluminum hydroxide played an important role in the removal of $\mathrm{PO}_{4}{ }^{3+}$, especially orthophosphate [12]; the removal effect of $\mathrm{P}$ depended on the adsorption capacity and distribution of flocs, rather than chemical precipitation [13]; the adsorption and removal of phosphorus was mainly through a complexation reaction under a special force rather than an aluminum phosphate precipitation [14]. The study had shown that the optimal ratio of aluminum salt to phosphorus in MBR effluent was 1.5 at $\mathrm{pH} 7.5$, which was lower than it in this experiment, probably because the stirring method of their experiment in a beaker was first fast and then slow, which was more conducive to adjustment [15].

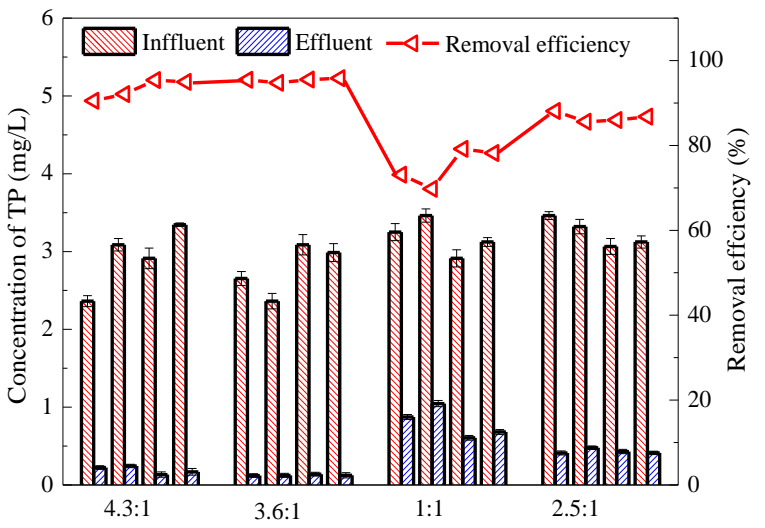

Fig. 3. The concentration of TP in the influent and effluent and its removal efficiency in different ratios of $\mathrm{AlCl}_{3}$ to TP.

\section{Conclusions}

In summary, we constructed a continuous flow chemical dephosphorization reactor to study the dephosphorization effect on the IF-MBR effluent. Removal effect of TP by four coagulants of $\mathrm{AlCl}_{3}, \mathrm{FeCl}_{3}, \mathrm{PAFC}$ and PAC was evaluated. Experiments show that in the case of excessive flocculants, the removal effect of $\mathrm{FeCl}_{3}$ was worst among the four flocculants. Its optimal efficiency was $92.5 \%$, while the removal rates of the other three flocculants were above $96 \%$. The removal effect of PAC and PAFC was good, but the flocs produced were small and light, and were not easy to precipitate. Therefore, $\mathrm{AlCl}_{3}$ was selected in the experiment. Analysis of the different addition ratio of $\mathrm{Al} / \mathrm{P}$ found that when the ratio was above $1: 1$, the effluent TP was less than $1 \mathrm{mg} / \mathrm{L}$; when the ratio was above $2.5: 1$, the effluent TP was below $0.5 \mathrm{mg} / \mathrm{L}$.

This study was supported by Grants from the science and technology project of SiChuan (No. 17DYF3097).

\section{References}

1. S.C. Qiu, Chemically ehanced pimary teatment thnology (CEPT), China Water Wastewater, 16, 26-29 (2000)

2. E. Diamadopoulos, C. Vlachos, Coagulation-filtration of a secondary effluent by means of pre-hydrolyzed coagulants, Water Sci. Technol. 33(10-11), 193-201 (1996)

3. J.Q. Jiang, N.J D. Graham, C. Harward, Comparison of polyferric sulphate with other coagulants for the removal of algae and algae-derived organic matter, Water Sci. Technol. 27, 221-230 (1993)

4. A. Adin, T. Asano, The role of physical-chemical treatment in wastewater reclamation and reuse, Water Sci. Technol. 37, 79-90 (1998)

5. K.C. Yu, T. Xue, X. Huang, J.L. Xia, C.S. Chen, T. Lei, J. Guan, X.H. Wen, Study and application of chemical phosphorus removal in MBR process for 
municipal wastewater treatment, Membrane Sci. Technol. 33, 81-85 (2013)

6. Y.L. Hou, Y.C. Liu, Y. Qiu, M. He, H.C. Shi, Effects of $\mathrm{Fe}^{3+}$ and $\mathrm{Al}^{3+}$ in the chemical-aid phosphorus removal drug on the activated sludge of the biological treatment system, Water Wastewater, 36, 38-41 (2010) (In Chinese)

7. N. Liu, X.G. Chen, Y.Z. Cui, J.S. Liu, X.X. Xu, Research progress of chemical dephosphorization process, Chemical Industry Engineering Progress, 31, 1597-1603 (2012) (In Chinese)

8. SEPA, Standard methods for the examination of water and wastewater, Chinese Environmental Science Press (2002)

9. Y. Li, C. Qin, Y. Ping, L. Wei, T. Xiao, Simultaneous organic carbon and nitrogen removal by heterotrophic nitrifers under oxygen-limited condition in an interloop fluidized membrane bioreactor, Desalination and Water Treatment, 18, 142-157(2018).
10. T. Coradin, J. Livage, Effect of some amino acids and peptides on silicic acid polymerization, Colloid Surface B:Biointerfaces, 21(4), 329-336 (2001)

11. D. Solberg, L. Wagberg, Adsorption and flocculation behavior of cationic polyacrylamide and colloidal silica, Colloids surfaces A:Physicochemical Engineering Aspects, 219(1-3), 161-172 (2003)

12. E. Galarneau, R. Gehr, Phosphorus removal from wastewaters:experimental and theoretical support for alternative mechanisms, Wat. Res. 31, 328-338 (1997)

13. E. Rydin, E.B Welch, Aluminum dose required to inactivate phosphate in lake sediments, Wat. Res. 32 2969-2976 (1998)

14. J.P. Boisbert, T.C. To, A. Berrak, C. Jolicoeur, Phosphate adsorption in flocculation processes of aluminium sulphate and poly-aluminium-silicatesulphate, Wat. Res. 31, 1939-1946 (1997)

15. B. Sun, Y.F. Zhang, Z.C. Wu, Research on the rear chemical phosphorus removal of MBR, Environmental Engineering, (S1), 61-64 (2014) 